\title{
The impact of surgical simulation on patient outcomes: a systematic review and meta-analysis
}

\author{
Trym R. Meling ${ }^{1} \cdot$ Torstein R. Meling ${ }^{1,2,3}$ (B) \\ Received: 19 March 2020 / Revised: 16 April 2020 / Accepted: 29 April 2020 / Published online: 13 May 2020 \\ (C) The Author(s) 2020
}

\begin{abstract}
The use of simulation in surgical training is ever growing. Evidence suggests such training may have beneficial clinically relevant effects. The objective of this research is to investigate the effects of surgical simulation training on clinically relevant patient outcomes by evaluating randomized controlled trials (RCT). PubMed was searched using PRISMA guidelines: "surgery" [All Fields] AND "simulation" [All Fields] AND "patient outcome" [All Fields]. Of 119 papers identified, 100 were excluded for various reasons. Meta-analyses were conducted using the inverse-variance random-effects method. Nineteen papers were reviewed using the CASP RCT Checklist. Sixteen studies looked at surgical training, two studies assessed patient-specific simulator practice, and one paper focused on warming-up on a simulator before performing surgery. Median study population size was 22 (range 3-73). Most articles reported outcome measures such as post-intervention Global Rating Scale (GRS) score and/or operative time. On average, the intervention group scored 0.42 (95\% confidence interval 0.12 to $0.71, P=0.005$ ) points higher on a standardized GRS scale of $1-10$. On average, the intervention group was $44 \%$ (1\% to $87 \%, P=0.04$ ) faster than the control group. Four papers assessed the impact of simulation training on patient outcomes, with only one finding a significant effect. We found a significant effect of simulation training on operative performance as assessed by GRS, albeit a small one, as well as a significant reduction to operative time. However, there is to date scant evidence from RCTs to suggest a significant effect of surgical simulation training on patient outcomes.
\end{abstract}

Keywords Education $\cdot$ Meta-analysis $\cdot$ Neurosurgery $\cdot$ Patient outcome $\cdot$ Simulation $\cdot$ Surgery $\cdot$ Systematic review

\section{Introduction}

Surgical training has traditionally been based on an apprenticeship model [1,2], to which there are substantial benefits. Prime among them is authenticity; one is exposed to all the concerns, pressures, and emotions that surgical practice entails. Furthermore, expert surgeons may use the operating room (OR) as a classroom [2], providing apprentices with

Electronic supplementary material The online version of this article (https://doi.org/10.1007/s10143-020-01314-2) contains supplementary material, which is available to authorized users.

Torstein R. Meling

torsteinrmeling@gmail.com

1 Faculty of Medicine, University of Oslo, Oslo, Norway

2 Department of Clinical Neurosciences, Division of Neurosurgery, Geneva University Hospitals, Rue Gabriel-Perret-Gentil 5, 1205 Geneva, Switzerland

3 Faculty of Medicine, University of Geneva, Geneva, Switzerland instruction and feedback in a live setting, thus enhancing the role of the expert as a scaffold for the trainee [3]. However, this model has some important drawbacks. With the modernday focus on ethical treatment standards [4], there is concern about "learning on the job" and its implications for patient safety $[5,6]$. In the current climate of long waiting lists and schedules swamped by consultations and paperwork, the ethical and monetary costs to spending the time of expert surgeons necessary to train novices have never been higher [7, 8]. Furthermore, legislation has been introduced in Europe and the USA to limit the work hours of surgical residents $[9,10]$. The European Working Time Directive was designed to prevent excessively long work hours [11], and thus, by extension, better and safer patient care. However, concerns have been raised about unintended consequences [9, 12, 13], such as dilution to the quantity and quality of training opportunities [12].

This has prompted the exploration of alternatives, such as simulation tools [14], that range from the basic table-top box trainer, to porcine cadavers, and state-of-the-art virtual reality 
(VR) simulators [15-26]. Such tools may potentiate the amount of repetitions necessary to gain automaticity in surgical techniques $[2,27]$, provide a risk-free environment in which no patients health is in jeopardy [28, 29], and allow for practice of procedures that are performed infrequently. Simulation centers can be accessible around the clock, allowing for considerable flexibility in scheduling. Another interesting prospect is the possibility of establishing a baseline of competence on simulators that must be shown by residents before being allowed to advance, giving trainees and their supervisors confidence in ability and ensuring a certain performance standard in the OR [30].

When investigating novel modes of teaching, it is important to establish benefits, as well as limitations [14]. It has been shown that practice of skills in a simulated setting leads to improvement of those skills when tested in that same environment [31-33], but this outcome appears self-evident. To the authors of this paper, a natural area of inquiry is transferability to the clinical setting. For example, maneuvering a colonoscope while wearing a VR headset is a different milieu to performing the examination on an uneasy patient or that the concerns when operating on a human patient differ from those when manipulating the tissues of an anesthetized pig. So, to what extent does surgical simulation training translate to performance in the OR and more importantly, what are its effects on clinically relevant patient outcomes? To answer this query, a systematic review of the relevant literature on surgical simulation skills training was conducted.

\section{Methods}

Evaluation of studies on simulation training was performed according to the Preferred Reporting Items for Systematic Reviews and Meta-Analyses (PRISMA) statement, including the methods of publication search, eligibility, data collection, extraction, and analysis, as well as preparation of the systematic review report $[34,35]$. Patients and the public were not involved in this research.

A study protocol was created, available as a supplemental file (Supplemental Digital Content File 1). A search of PubMed databases using the following criteria "surgery" [All Fields] AND "simulation" [All Fields] AND "patient outcome" [All Fields] was performed on January 7, 2019. The following search filters were applied: human species and randomized controlled trial article type. A PRISMA flow diagram was created in order to visualize this process (Fig. 1) [36]. The literature search produced 119 papers, the abstracts of which were reviewed by two raters to determine eligibility as per convention to determine relevancy (Supplemental Digital Content File 2). Studies were excluded if they did not involve surgery (e.g., vaginal child delivery) or if the simulation described lacked involvement of manual skills (e.g., three-dimensional reconstruction of a cyst to plan surgery). This resulted in the exclusion of 75 papers. Studies were further excluded if no patient treatments were conducted or if all measurements were recorded in a simulated setting. This led to the removal of another 25 papers. The full text of the remaining 19 papers were reviewed using the Critical Appraisal Skills Programme (CASP)-Randomized Controlled Trial (RCT) Checklist as a guide (Supplemental Digital Content File 3) [37].

Information sought in each paper was the following: study population enrolled, study population in the final analysis, training level of study population, type of procedure studied, whether or not an OR baseline was established, use of intraoperative rating scale, recording of operative time, type of simulation used, time allotted to simulation training, type of training control group received, if the intervention group was significantly better than the control group after intervention, clinically relevant effects of training, if intervention group improved from its baseline following intervention, and effect of intervention on patient outcomes.

Study quality was assessed by evaluating the mode of randomization used, if the trial was stopped early, if patient assignment was truly randomized (that is to say, assignment was done by a random number generator or similar process, not merely dependent on the surgical staff rotation), blinding of patients and data collectors, accounting of subjects at trial conclusion, evidence of selective reporting, and similarity of groups at the start of the trial.

Patient outcomes were defined as data or measurements of patients made after surgical intervention; in-hospital and 30day mortality, as well as postoperative complications, for example. In contrast, operative time and subjective assessments of perioperative errors were not considered patient outcomes.

Study data measured in a clinical setting (i.e., on real patients, not in a simulated environment) were extracted by the first author and added to a data sheet (Supplemental Digital Content File 4). One study was reported in two separate papers, one of which was identified in our literature search (Desender et al. [38]) and included in the final review. Relevant data and results were extracted from the other paper [39] and are considered one under the guise of the former, as they share the same first author.

The majority of the articles reported outcome measures such as Global Rating Scale (GRS) score and operative time. Rating scales are tools for the objective evaluation of an individual's skill, as assessed by experts or trained personnel. Typically, they consist of seven items, scored on a Likert scale of 1-5 [40]. Many such instruments are in use; they may concern general operative performance or be specific to a certain procedure $[41,42]$. There is some heterogeneity in terms of number of items (e.g., 4 or 10) as well as Likert scale range employed by different GRSs. To accommodate this and allow for the combination of data, an arbitrary scale of 1-10 
was created by authors in order to standardize values across studies. The GRS used by each study was then mapped to this arbitrary scale and a standardized mean was calculated (Supplemental Digital Content File 5). In cases where a study used multiple rating scales, the most generic one was chosen.

Different surgical procedures require different amounts of time to complete. Thus, to compare operative times, the mean result of the intervention group and that of the control group was divided by the result of the control group. In this way, the control mean becomes 1 for all studies, and the intervention mean is expressed as a fraction of the control, with a value smaller or larger than 1, depending on whether the group was faster or slower (Supplemental Digital Content File 5).

If a study had more than two groups, the control group was compared with the main intervention group. If groups were tested at multiple times, the results of the first test postintervention were used. If a paper reported $95 \%$ confidence intervals $(\mathrm{CI})$, the standard deviation was calculated (Supplemental Digital Content File 5). Papers that reported results only as median values were excluded from synthesis. In cases of incomplete data reporting, attempts were made to calculate necessary values (from given $P$ values, for example). If such attempts were unsuccessful, the study was excluded from data synthesis. Lack of significant differences between intervention and control groups was not a cause for exclusion from data synthesis. These actions were observed in accordance with the Cochrane Collaboration's guidelines on conducting meta-analyses outlined in Part 2, Chapter 9 of the Cochrane Handbook for Systematic Reviews of Interventions [43].

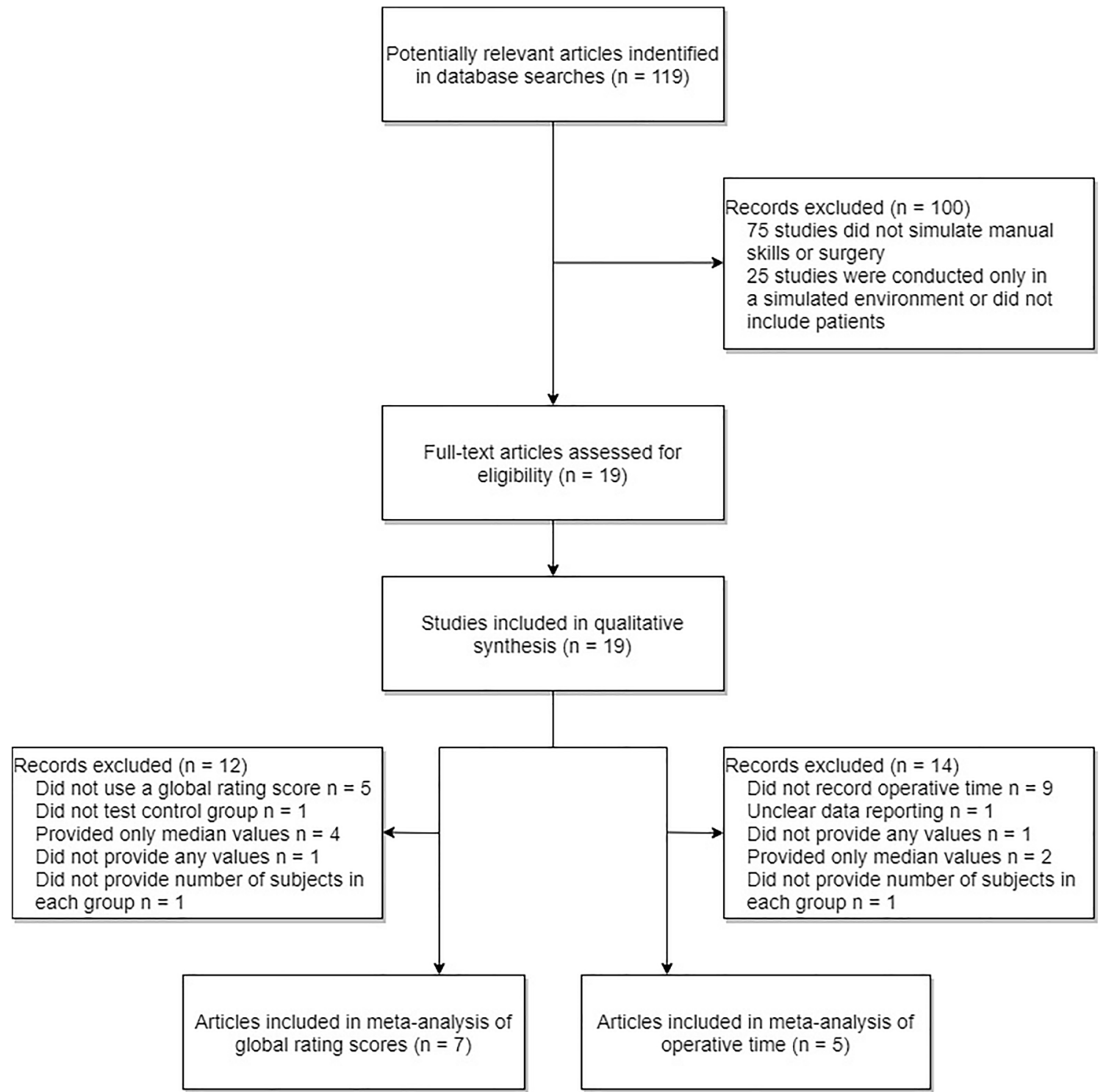

Fig. 1 PRISMA flow diagram visualizing the literature search. A total of 119 papers were identified in our literature search. One hundred of these were excluded; the remaining 19 papers were assessed for eligibility and

subsequently included in qualitative analysis. Of these, seven were eligible for inclusion in our meta-analysis of global rating scores and six in our analysis of operative time 
Table 1 Key characteristics of the 19 papers included in the study

\begin{tabular}{|c|c|c|c|c|c|}
\hline Authors & $\begin{array}{l}\text { No. of participants } \\
\text { enrolled* }\end{array}$ & $\begin{array}{l}\text { No. in final } \\
\text { analysis** }\end{array}$ & $\begin{array}{l}\text { Training level of } \\
\text { study population }\end{array}$ & Procedure simulated & Type of simulator \\
\hline Wooster et al. [27] & 3 & 3 & Expert surgeons & Endovascular (carotid stenting) & VR \\
\hline Maertens et al [41] & 32 & 29 & Surgical residents & Endovascular (angioplasty) & VR \\
\hline Zevin et al. ${ }^{56}$ & 20 & 8 & Surgical residents & Laparoscopic (bariatric surgery) & Porcine model \\
\hline Desender et al. [29] & NA & NA & Expert surgeons & Endovascular (EVAR) & VR \\
\hline Nilsson et al. [17] & 36 & 35 & Medical students & Endoscopic (camera navigation) & VR \\
\hline Waterman et al. [46] & 22 & 22 & Surgical residents & Endoscopic (shoulder arthroscopy) & VR \\
\hline Shore et al. [15] & 27 & 21 & Surgical residents & Laparoscopic (salpingectomy) & VR and box trainer \\
\hline Patel et al. [16] & 22 & 22 & Surgical residents & Laparoscopic (salpingectomy) & Porcine model \\
\hline Dunn et al. [47] & 17 & 17 & Surgical residents & Endoscopic (shoulder arthroscopy) & VR \\
\hline Peltan et al. [29] & 73 & 51 & Internal medicine residents & CVC placement (internal jugular vein) & Box trainer \\
\hline Grover et al. [42] & 34 & 33 & $\begin{array}{l}\text { Surgical and internal } \\
\text { medicine residents }\end{array}$ & Endoscopy (colonoscopy) & VR \\
\hline Carlsen et al. [48] & 18 & 16 & Surgical residents & Open hernia repair (Lichtenstein) & $\begin{array}{l}\text { Porcine model } \\
\text { and box trainer }\end{array}$ \\
\hline Koch et al. [49] & 18 & 18 & Internal medicine residents & Endoscopic (colonoscopy) & VR \\
\hline Zendejas et al. [14] & 50 & 50 & Surgical residents & Laparoscopic (TEP inguinal hernia repair) & Box trainer \\
\hline Kessler et al. [6] & 56 & 32 & Pediatric residents & Infant lumbar puncture & Box trainer \\
\hline Calatayud et al. [30] & 10 & 8 & Surgical residents & Laparoscopic (cholecystectomy) & VR \\
\hline Haycock et al. [50] & 40 & 36 & Medical practitioners & Endoscopic (colonoscopy) & VR \\
\hline Ahlberg et al. [2] & 13 & 13 & Surgical residents & Laparoscopic (cholecystectomy) & VR \\
\hline Cohen et al. [51] & 51 & 45 & Internal medicine fellows & Endoscopic (colonoscopy) & VR \\
\hline
\end{tabular}

*Study population refers to number of surgeons

**Number of completed VR cases; group i was tested twice in patient after 10, 30, and 50 VR cases completed; group ii was tested twice in patients after 20,60 , and 100 VR cases completed

Data processing was accomplished with the aid of Wolfram|Alpha [44]. Meta-analyses were performed using the Cochrane Collaboration's Review Manager software [45]. Standardized means were compared with the inversevariance random-effects method. The effect size is the standardized mean difference, Hedge's (adjusted) $g$ [43]. Heterogeneity was assessed using the $\mathrm{chi}^{2}$ and $I^{2}$ tests.

\section{Results}

We assessed and included a total of 19 studies in this review. Sixteen studies looked at surgical training, two studies assessed patient-specific simulator practice prior to the actual procedure, and one paper focused on warming-up on a simulator before performing surgery. The median number of enrolled operators was 22 (range 3-73). Ten of the papers assessed surgical residents, two assessed expert surgeons, and the remainder assessed people from other medical backgrounds (Table 1).

The procedures studied were endoscopic $(n=7)$, laparoscopic $(n=6)$, endovascular $(n=3)$, central venous catheter $(\mathrm{CVC})$ placement $(n=1)$, open hernia repair $(n=1)$, and lumbar puncture $(n=1)$. Five papers established a baseline in the OR before administering the intervention. VR simulators were most commonly used $(n=12)$ for the training intervention; other simulators included box trainers $(n=3)$, porcine models $(n=2)$, and a combination of these $(n=2)$ (Table 1$)$.

The duration of the simulator training differed across the studies included in this review. In most studies, the intervention group practiced for a certain amount of time; five for $2 \mathrm{~h}$ or less, five for more than $2 \mathrm{~h}$. Six studies used a predetermined measure of proficiency (such as completing a given task with no mistakes or in a certain amount of time) to determine when an enrollee was ready for testing. Two studies practiced on simulated patient-specific anatomy prior to the actual surgery, with the control group in one of these rehearsing the patient's anatomy after performing the real procedure. One paper administered simulation training to both its groups, testing them after different numbers of completed cases on a VR simulator. In most of the studies, the control groups merely continued with conventional residency training $(n=12)$ or received no training at all $(n=2)$. In other cases, surgeons served as their own control $(n=1)$, practiced on a simulator without receiving instruction or feedback $(n=1)$, or practiced on real patients instead of on a simulator $(n=1)$ (Table 2). 


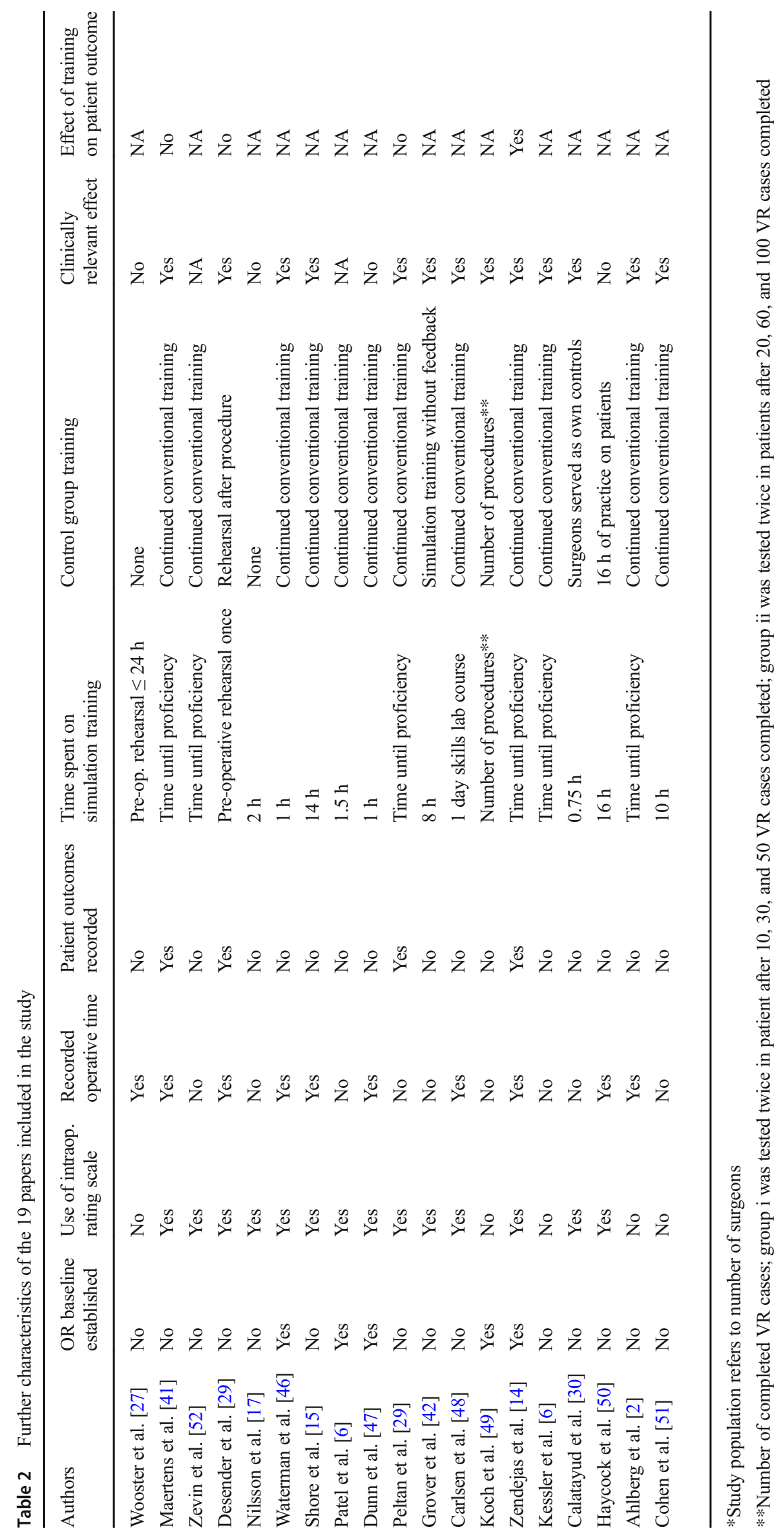


In terms of recorded measurements, 14 studies used some form of intraoperative rating scale and 10 studies recorded operative time. Thirteen studies showed a statistically significant difference (of any measure) between control and intervention group at first testing after the intervention; four studies did not find any significant differences, and analysis was not available from two (Table 2). Of the 13 papers that found a significant difference between the intervention and control group, all 13 were judged by the authors of this review to be potentially clinically significant. However, only four of these studies assessed patient outcomes and three found no significant effect of intervention. This was visualized using a flow chart (Fig. 2).

The paper that did find a significant effect of intervention on patient outcome was by Zendejas and colleagues [14], who looked at simulation training of laparoscopic total extraperitoneal repair of inguinal hernias. Their intervention consisted of an online skills course followed by a multiplechoice questionnaire, after which subjects completed a skills course on a box trainer. Participants were required to complete the assigned task in under 2 min on two consecutive attempts. At post-intervention assessment in the OR, the intervention group was significantly faster, achieved higher GRS scores, and made fewer intraoperative errors. Furthermore, their surgeries resulted in fewer postoperative complications (urinary retention, seroma, hematoma, or wound infection) and overnight hospital stays. Hernia recurrence and groin pain at 3month follow-up were similar between the control and intervention groups.

Risk of bias and study quality were also assessed, the main results of which are presented in Table 3. Sixteen studies reported how their trial was randomized. One trial was stopped early. Only two papers used a random number generator (or similar tool) to assign patients to study participants. Only two of the papers reviewed reported adequate blinding of patients to the training status of the subject performing their surgery. In 15 studies, all data collectors were blinded to the group subjects belonged to. Only one study did not adequately account
Fig. 2 Flow chart visualizing the results of included studies, including the number of papers that demonstrated a clinical effect and/or effect on patient outcomes

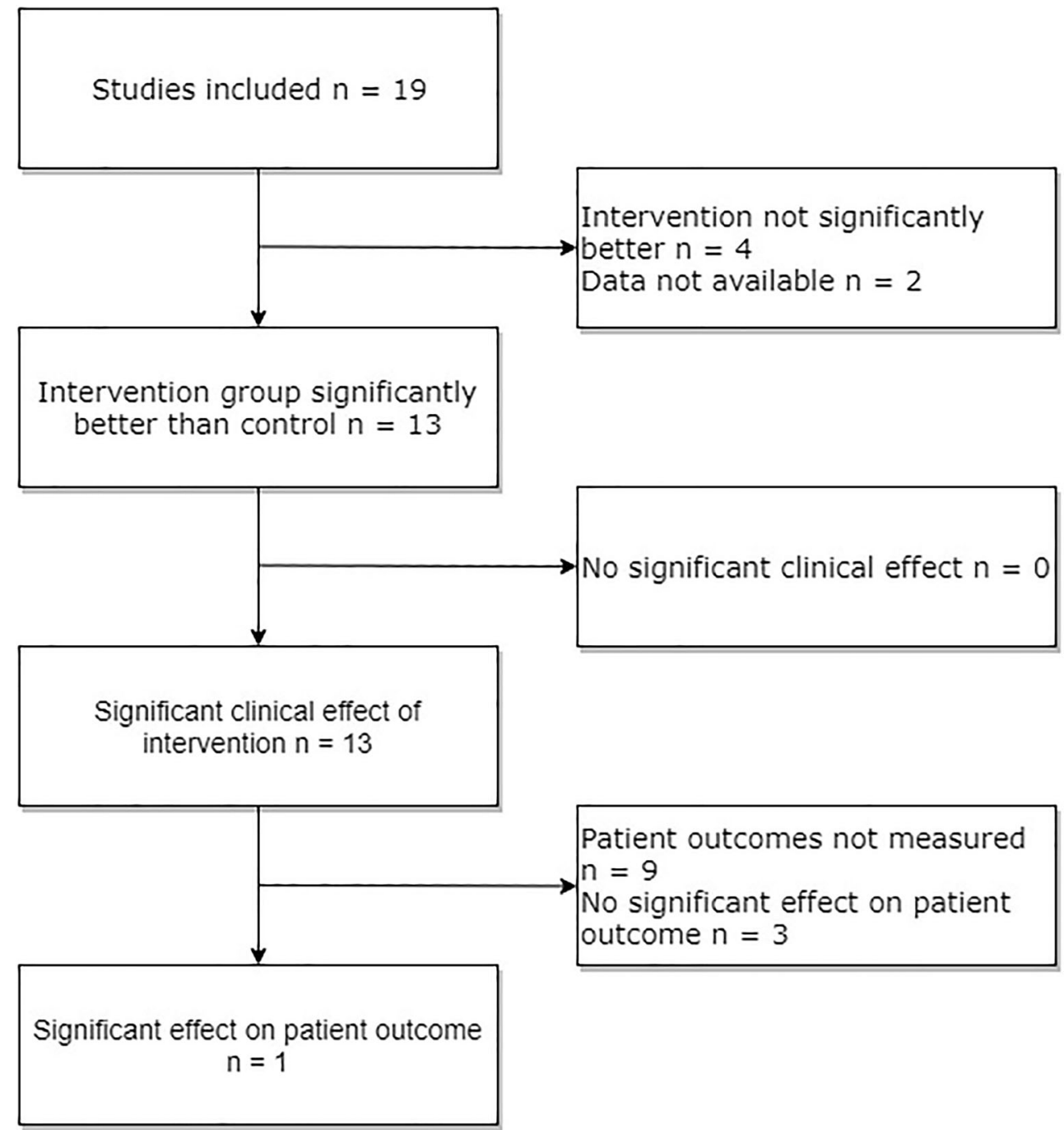




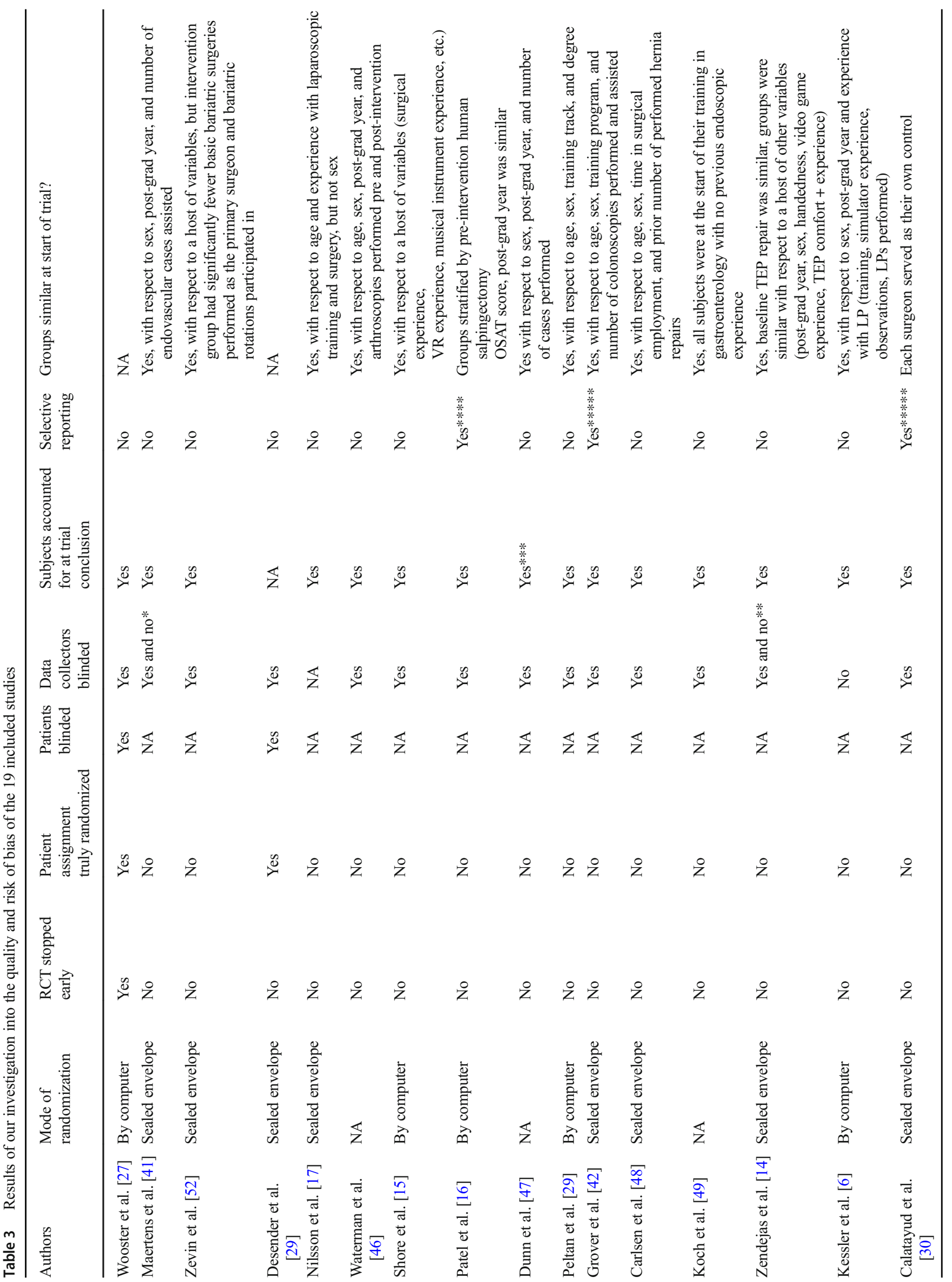


for all enrolled subjects at the conclusion of the trial. Seventeen studies reported data on the similarity of its groups at the start of the trial.

\section{Effect on Global Rating Scale}

Fourteen papers evaluated its subjects using a GRS. Of these, four studies were excluded due to only reporting median values and one due to not testing its control group outside of a simulated setting. One study only presented statistical analysis without reporting raw data or means; attempts were made to reconstruct these values without success. One study presented the total number of subjects enrolled, without mentioning the sizes of its control and intervention group. Attempts were made to calculate this given reported $P$ values, but to no avail. As such, only a total of seven studies had the necessary data quality to be included in our analysis.

The standardized mean difference was 0.54 (95\% confidence interval 0.14 to $0.94, P=0.009$ ) (Fig. 3a). Thus, in these seven papers, the intervention group scored on average 0.54 points higher on our standardized scale of 1-10. Both lower and upper $95 \%$ CIs are above zero. The $I^{2}$ value is $45 \%$, indicating moderate heterogeneity [43]. As the paper by Maertens and colleagues [41] seemed to be an outlier, we explored what effect it would have on our results to exclude it from analysis. The standardized mean difference drops slightly to $0.42(0.12$ to $0.71, P=0.005)$. However, $I^{2}$ falls dramatically to $0 \%$ (Fig. $3 b$ ).

\section{Effect on operative time}

Ten papers recorded operative times. Of these, two reported only median values and were excluded. One paper reported mean values, but failed to explicitly state if the accompanying values were ranges or $95 \%$ confidence intervals, and was thus excluded. One study presented only data analysis without reporting raw data or means; attempts were made to reconstruct these values without success. One study presented the total number of subjects enrolled, without mentioning the sizes of its control and intervention group. Attempts were made to calculate this given reported $P$ values, but to no avail. Thus, a total of five studies had sufficient data quality to be included in our analysis of operative time differences.

The standardized mean difference after simulator training was -0.23 ( -0.80 to $0.34, P=0.43$ ) (Fig. 4a). Hence, the intervention group was on average $23 \%$ faster than the control group, but notably, the confidence interval is large and lies on both sides of 0 . Heterogeneity is substantial [43], as indicated by an $I^{2}$ value of $71 \%$.

The study by Maertens and colleagues [41] was deemed to be an outlier (in the analysis of GRSs); thus, we again explored the effects of excluding it. Standardized mean difference becomes slightly larger with a value of $-0.44(-0.86$ to 
$-0.01, P=0.04)$. The confidence interval is slimmer and no longer intersects zero. Furthermore, heterogeneity is lower $\left(I^{2}\right.$ $=42 \%)$ (Fig. 4b).

\section{Discussion}

Over the past few decades, there has been increasing interest in simulation technology in the field of surgery. There are multiple reasons for this, among them are technological advances that allow for increasing fidelity [53], residency work hour restrictions necessitating a shift of surgical education to outside ORs [9, 10, 12, 13,54], and a changing medico-legal landscape concerning treatment standards [5]. However, the question is whether the enthusiasm in the field has translated to robust evidence regarding the benefits of simulation training.

In this review, using the PRISMA guidelines, we identified only 19 RCTs that investigated the impact of simulation training on the surgical treatment of patients. Study population size varied widely (range 3-73). Most of the procedures studied were endoscopic or laparoscopic in nature, and the enrolled subjects were predominantly residents (Table 1 ). Training primarily occurred on VR simulators, either for a fixed amount of time or until a predetermined level of proficiency was achieved (Table 2). However, only five papers established a performance baseline in the OR. Outcome measures in a clinical setting (not in a simulated environment) were diverse, but frequently, only a GRS of operative performance was used (Supplemental Digital Content File 4).

Study quality was mixed; only two trials appropriately randomized and blinded patients, and there were multiple instances of data collectors not being blinded (Table 3 ). Several papers had a high risk of selective reporting (Table 3). As such, our conclusions are tempered, but in line with previous systematic reviews and meta-analyses on the topic [55-57].

Thirteen of the studies found statistically significant effects of training on outcomes measured in the OR. Although these effects were deemed to be potentially clinically relevant, arguably, the most essential measure in surgery is patient outcome. Merely four of our included studies assessed the impact of simulation training on patient outcomes, and only one found a significant effect (Fig. 2).

With regard to meta-analyses, we synthesized the results of the overall effect of simulation training on operative performance. When standardized to a GRS scale from 1 to 10 , participants who received simulation training scored an average of 0.42 points higher than their control group peers after intervention $(P=0.005)$ (Fig. 3b). Thus, there seems to be a positive effect of simulation training on performance as measured by a GRS, albeit a small one. Interestingly, chi ${ }^{2}$ and $I^{2}$ tests of this analysis were low, indicating that this result was homogenous across included studies (Fig. 3b). Similarly, when operative times were standardized, simulation-trained participants were $44 \%$ faster $(P=0.04)$ (Fig. 4 b), although

a

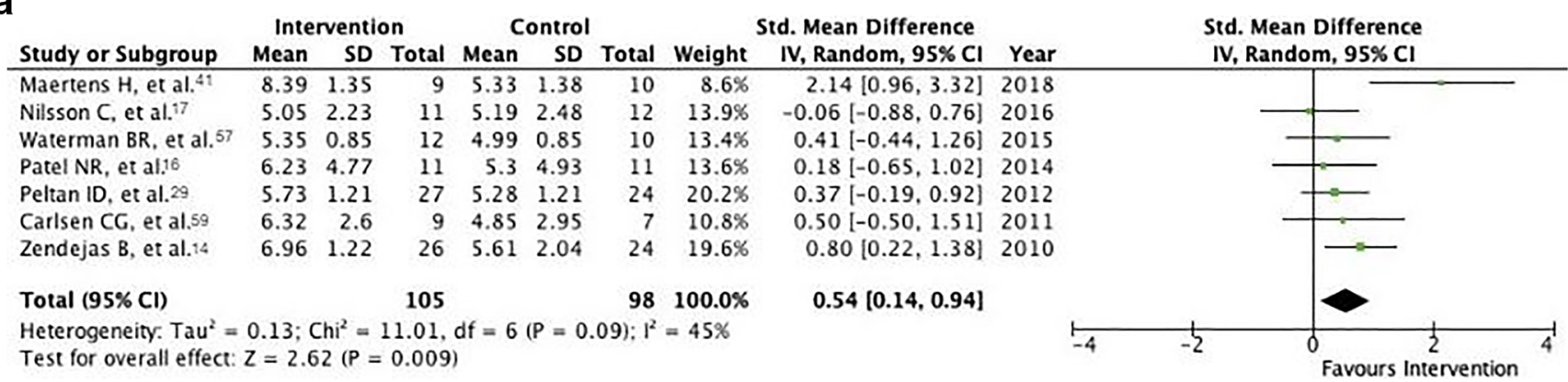

b

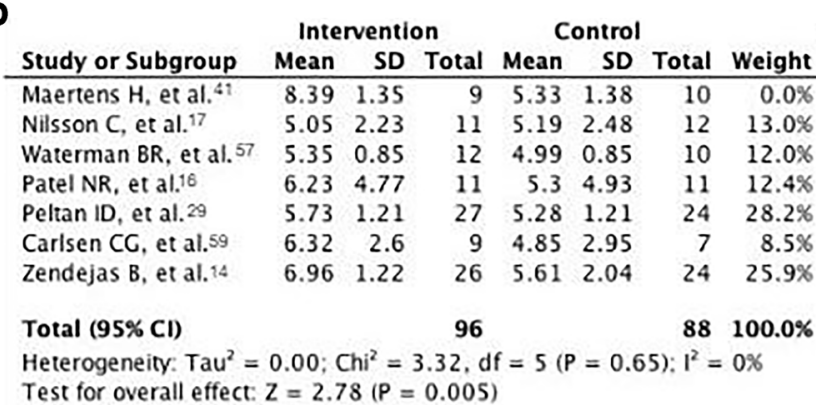

Fig. 3 a Forest plot of the standardized mean difference of GRS scores between control and intervention groups, including tests for heterogeneity. b Forest plot of the standardized mean difference of GRS

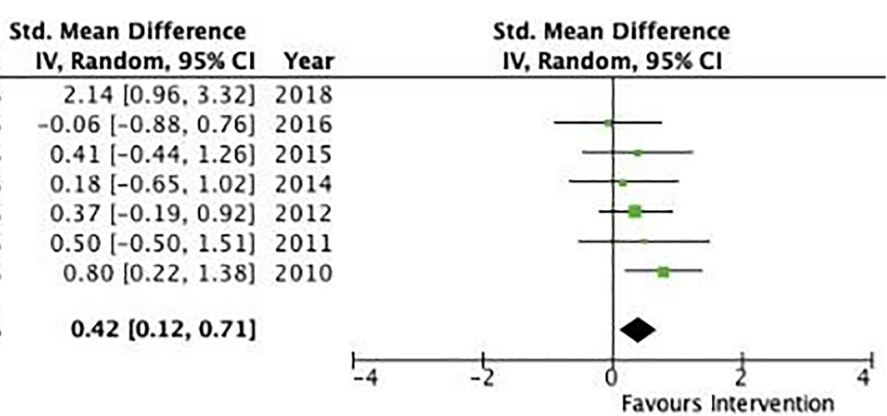

scores between control and intervention groups with outlier removed, including tests for heterogeneity 


\begin{tabular}{|c|c|c|c|c|c|c|c|c|c|}
\hline \multirow[b]{2}{*}{ Study or Subgroup } & \multicolumn{3}{|c|}{ Intervention } & \multicolumn{3}{|c|}{ Control } & \multicolumn{3}{|c|}{ Std. Mean Difference } \\
\hline & Mean & SD & Total & Mean & SD & Total & Weight & IV, Random, $95 \% \mathrm{CI}$ & Yea \\
\hline Maertens $\mathrm{H}$, et al. ${ }^{41}$ & 1.2 & 0.17 & 9 & 1 & 0.18 & 10 & $16.2 \%$ & $1.09[0.11,2.07]$ & 2018 \\
\hline Desender $\mathrm{L}$, et al. ${ }^{38}$ & 0.95 & 0.4427 & 50 & 1 & 0.46 & 50 & $27.0 \%$ & $-0.11[-0.50,0.28]$ & 2017 \\
\hline Waterman BR, et al. ${ }^{57}$ & 0.89 & 0.4534 & 12 & 1 & 0.46 & 10 & $18.5 \%$ & $-0.23[-1.07,0.61]$ & 2015 \\
\hline Carlsen CG, et al. ${ }^{59}$ & 0.65 & 0.1773 & 9 & 1 & 0.48 & 7 & $14.9 \%$ & $-0.97[-2.03,0.09]$ & 2011 \\
\hline Zendejas 8 , et al. ${ }^{14}$ & 0.83 & 0.1952 & 26 & 1 & 0.22 & 24 & $23.5 \%$ & $-0.81[-1.39,-0.23]$ & 2010 \\
\hline Total $(95 \% \mathrm{Cl})$ & & & 106 & & & 101 & $100.0 \%$ & $-0.23[-0.80,0.34]$ & \\
\hline
\end{tabular}

b

\begin{tabular}{|c|c|c|c|c|c|c|c|c|c|}
\hline \multirow[b]{2}{*}{ Study or Subgroup } & \multicolumn{3}{|c|}{ Intervention } & \multicolumn{3}{|c|}{ Control } & \multicolumn{3}{|c|}{ Std. Mean Difference } \\
\hline & Mean & SD & Total & Mean & SD & Total & Weight & IV, Random, 95\% Cl & Year \\
\hline Maertens $\mathrm{H}$, et al. ${ }^{41}$ & 1.2 & 0.17 & 9 & 1 & 0.18 & 10 & $0.0 \%$ & $1.09[0.11,2.07]$ & 2018 \\
\hline Desender $L$, et al. ${ }^{38}$ & 0.95 & 0.4427 & 50 & 1 & 0.46 & 50 & $40.1 \%$ & $-0.11[-0.50,0.28]$ & 2017 \\
\hline Waterman BR, et al. ${ }^{57}$ & 0.89 & 0.4534 & 12 & 1 & 0.46 & 10 & $18.2 \%$ & $-0.23[-1.07,0.61]$ & 2015 \\
\hline Carlsen CG, et al. ${ }^{59}$ & 0.65 & 0.1773 & 9 & 1 & 0.48 & 7 & $12.9 \%$ & $-0.97[-2.03,0.09]$ & 2011 \\
\hline Zendejas B, et al. ${ }^{14}$ & 0.83 & 0.1952 & 26 & 1 & 0.22 & 24 & $28.8 \%$ & $-0.81[-1.39,-0.23]$ & 2010 \\
\hline Total $(95 \% \mathrm{Cl})$ & & & 97 & & & 91 & $100.0 \%$ & $-0.44[-0.87,-0.01]$ & \\
\hline
\end{tabular}

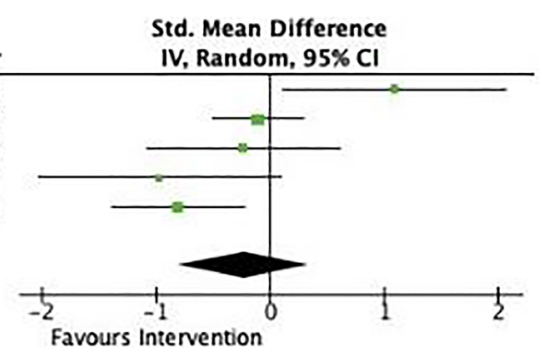

Fig. 4 a Forest plot of the standardized mean difference of operative time between control and intervention groups, including tests for heterogeneity. b Forest plot of the standardized mean difference of

heterogeneity of this analysis was moderate. This may in part be due to the inclusion of studies from different surgical fields; the difference in operative time of a novice compared with a master is unlikely to be the same across all types of procedures.

There are limitations to our study, prime among them being that few papers were included in qualitative analysis $(n=19)$, although we contend that this reflects the literature as a whole. As a result of diversity in recorded outcomes and stringent criteria for entry into data synthesis, our meta-analysis is based on an even smaller amount of studies ( $n=6$ for GRS and $n=4$ for operative time). Furthermore, we included studies from various surgical fields, the results of which may not be comparable. Subgroup analyses were not conducted; we did not compare training for a given amount of time to training until reaching proficiency, or the effect of the training level of the study population on the effect of intervention, for example. Only one author was responsible for reviewing and excluding papers identified in our literature search, as well as for extracting data from included studies; this may have introduced bias to our findings.

Few systematic reviews have studied the impact of surgical simulation training on patient outcomes. Zendejas and colleagues found "small-moderate patient benefits," although notably, their field of study was wider (all medical education) and patient outcomes were defined more broadly, including technical success of the procedure [56]. We chose not to include intraoperative errors and procedural success as patient outcomes, as they may be subject to a variety of interpretations operative time between control and intervention groups with outlier removed, including tests for heterogeneity

(e.g., when is patient discomfort during a colonoscopy the result of poor scope movement and when is it an unavoidable result of strictures?) [58].

We found a positive effect of simulation training on achieved GRS score, as well as operative time; a finding that is echoed in the literature [55, 57, 59]. However, it must be noted that rating scales and operative time are surrogates of surgical proficiency and that technical surgical skills cannot be determined by one simple measure [57]. Scales such as the OSATS and OSA-LS have been thoroughly tested and show high inter-rater reliability [40], but are nevertheless based on subjective reflections made by observers [60]. Operative time may be a misleading metric; although expert surgeons perform procedures faster than residents [61], time at the cost of patient well-being is an unacceptable trade-off [62].

Whether or not the noted improvements are costeffective requires further research. Aside from the initial expenses of necessary equipment, a host of other variables associated with implementation seem likely to be important. For example, can simulation training occur outside of work hours, or must it be added to existing schedules? Given the latter, do residents have spare time to accommodate this change or must it supplant other activities? Will simulation training come at the expense of time in the OR? Can training occur with an instructor? Crucially, the answers to these questions will not be identical across institutions, and as such, the efficacy of simulation training may vary.

To conclude, simulation training has a positive effect on OR performance and operative time, although there is little 
substantial evidence to date to support a direct beneficial effect on patient outcomes.

Funding Information Open Access funding provided by University of Oslo (incl Oslo University Hospital).

\section{Compliance with ethical standards}

Conflict of interest The authors declare that they have no conflict of interest.

Ethical approval Not applicable as no new patients were involved in this research.

Informed consent Not applicable as no new patients were involved in this research

Open Access This article is licensed under a Creative Commons Attribution 4.0 International License, which permits use, sharing, adaptation, distribution and reproduction in any medium or format, as long as you give appropriate credit to the original author(s) and the source, provide a link to the Creative Commons licence, and indicate if changes were made. The images or other third party material in this article are included in the article's Creative Commons licence, unless indicated otherwise in a credit line to the material. If material is not included in the article's Creative Commons licence and your intended use is not permitted by statutory regulation or exceeds the permitted use, you will need to obtain permission directly from the copyright holder. To view a copy of this licence, visit http://creativecommons.org/licenses/by/4.0/.

\section{References}

1. Imber G (2010) Genius on the edge: the bizarre double life of Dr. William Stewart Halsted. Kaplan Pub, New York

2. Ahlberg G, Enochsson L, Gallagher AG et al (2007) Proficiencybased virtual reality training significantly reduces the error rate for residents during their first 10 laparoscopic cholecystectomies. Am J Surg. 193(6):797-804

3. Wood D, Wood H (1996) Vygotsky, Tutoring and learning. Oxford Rev Educ 22(1):5-16

4. Kohn LT, Corrigan J, Donaldson MS, Institute of Medicine (U.S.). Committee on Quality of Health Care in America (2000) To err is human: building a safer health system. National Academy Press, Washington, D.C.

5. Chief Medical Officer (2006) Good doctors, safer patients: proposals to strengthen the system to assure and improve the performance of doctors and to protect the safety of patients. Department of Health, Great Britain, London

6. Kessler DO, Auerbach M, Pusic M, Tunik MG, Foltin JC (2011) A randomized trial of simulation-based deliberate practice for infant lumbar puncture skills. Simul Healthc. 6(4):197-203

7. Benzekri R, Marie-Louise J, Chahed S (2017) Cost of teaching cataract surgery in a public hospital. J Fr Ophtalmol. 40(10):860864

8. Babineau TJ, Becker J, Gibbons G et al (2004) The "cost" of operative training for surgical residents. Arch Surg. 139(4):366-369 discussion 369-370

9. Fitzgerald JE, Caesar BC (2012) The European Working Time Directive: a practical review for surgical trainees. Int J Surg. 10(8):399-403
10. Nasca TJ, Day SH, Amis ES Jr, Force ADHT (2010) The new recommendations on duty hours from the ACGME Task Force. N Engl J Med. 363(2):e3

11. British Medical Association (2012) What is the European Working Time Directive? https:/www.bma.org.uk/advice/employment/ working-hours/ewtd. Accessed July 27, 2019

12. Stienen MN, Bartek J Jr, Czabanka MA et al (2019) Neurosurgical procedures performed during residency in Europe-preliminary numbers and time trends. Acta Neurochir (Wien). 161(5):843-853

13. Stienen MN, Netuka D, Demetriades AK et al (2016) Working time of neurosurgical residents in Europe-results of a multinational survey. Acta Neurochir (Wien). 158(1):17-25

14. Zendejas B, Cook DA, Bingener J et al (2011) Simulation-based mastery learning improves patient outcomes in laparoscopic inguinal hernia repair: a randomized controlled trial. Ann Surg. 254(3): 502-509 discussion 509-511

15. Shore EM, Grantcharov TP, Husslein H et al (2016) Validating a standardized laparoscopy curriculum for gynecology residents: a randomized controlled trial. Am J Obstet Gynecol 215(2):204 e201-204 e211

16. Patel NR, Makai GE, Sloan NL, Della Badia CR (2016) Traditional versus simulation resident surgical laparoscopic salpingectomy training: a randomized controlled trial. J Minim Invasive Gynecol. 23(3):372-377

17. Nilsson C, Sorensen JL, Konge L et al (2017) Simulation-based camera navigation training in laparoscopy-a randomized trial. Surg Endosc. 31(5):2131-2139

18. Shakur SF, Luciano CJ, Kania P et al (2015) Usefulness of a virtual reality percutaneous trigeminal rhizotomy simulator in neurosurgical training. Neurosurgery. 11(Suppl 3):420-425 discussion 425

19. Alotaibi FE, AlZhrani GA, Mullah MA et al (2015) Assessing bimanual performance in brain tumor resection with NeuroTouch, a virtual reality simulator. Neurosurgery. 11(Suppl 2):89-98 discussion 98

20. Rosseau G, Bailes J, del Maestro R et al (2013) The development of a virtual simulator for training neurosurgeons to perform and perfect endoscopic endonasal transsphenoidal surgery. Neurosurgery. 73(Suppl 1):85-93

21. Ray WZ, Ganju A, Harrop JS, Hoh DJ (2013) Developing an anterior cervical diskectomy and fusion simulator for neurosurgical resident training. Neurosurgery. 73(Suppl 1):100-106

22. Lobel DA, Elder JB, Schirmer CM, Bowyer MW, Rezai AR (2013) A novel craniotomy simulator provides a validated method to enhance education in the management of traumatic brain injury. Neurosurgery. 73(Suppl 1):57-65

23. Harrop J, Rezai AR, Hoh DJ, Ghobrial GM, Sharan A (2013) Neurosurgical training with a novel cervical spine simulator: posterior foraminotomy and laminectomy. Neurosurgery. 73(Suppl 1): 94-99

24. Fargen KM, Arthur AS, Bendok BR et al (2013) Experience with a simulator-based angiography course for neurosurgical residents: beyond a pilot program. Neurosurgery. 73(Suppl 1):46-50

25. Delorme S, Laroche D, DiRaddo R, Del Maestro RF (2012) NeuroTouch: a physics-based virtual simulator for cranial microneurosurgery training. Neurosurgery 71 (1 Suppl Operative): $32-42$

26. Spicer MA, van Velsen M, Caffrey JP, Apuzzo ML (2004) Virtual reality neurosurgery: a simulator blueprint. Neurosurgery. 54(4): 783-797 discussion 797-788

27. Wooster M, Doyle A, Hislop S et al (2018) REHEARSAL using patient-specific simulation to improve endovascular efficiency. Vasc Endovascular Surg. 52(3):169-172

28. Gladwell M (2008) Outliers: the story of success. Allen Lane, London

29. Peltan ID, Shiga T, Gordon JA, Currier PF (2015) Simulation improves procedural protocol adherence during central venous 
catheter placement: a randomized controlled trial. Simul Healthc. 10(5):270-276

30. Calatayud D, Arora S, Aggarwal R et al (2010) Warm-up in a virtual reality environment improves performance in the operating room. Ann Surg. 251(6):1181-1185

31. Grantcharov TP, Bardram L, Funch-Jensen P, Rosenberg J (2003) Learning curves and impact of previous operative experience on performance on a virtual reality simulator to test laparoscopic surgical skills. Am J Surg. 185(2):146-149

32. Gallagher AG, Satava RM (2002) Virtual reality as a metric for the assessment of laparoscopic psychomotor skills. Learning curves and reliability measures. Surg Endosc. 16(12):1746-1752

33. Stefanidis D, Korndorffer JR Jr, Sierra R, Touchard C, Dunne JB, Scott DJ (2005) Skill retention following proficiency-based laparoscopic simulator training. Surgery. 138(2):165-170

34. Moher D, Liberati A, Tetzlaff J, Altman DG, Group P (2009) Preferred reporting items for systematic reviews and meta-analyses: the PRISMA statement. BMJ. 339:b2535

35. Liberati A, Altman DG, Tetzlaff J et al (2009) The PRISMA statement for reporting systematic reviews and meta-analyses of studies that evaluate healthcare interventions: explanation and elaboration. BMJ. 339:b2700

36. The PRISMA Group (2009) PRISMA flow diagram. http://www. prisma-statement.org/PRISMAStatement/FlowDiagram. Accessed Jan 29, 2019

37. Critical Appraisal Skills Programme (2018) CASP Randomized Controlled Trial Checklist. https://casp-uk.net/wp-content/uploads/ 2018/01/CASP-Randomised-Controlled-Trial-Checklist-2018.pdf.

38. Desender L, Van Herzeele I, Lachat M et al (2017) A multicentre trial of patient specific rehearsal prior to EVAR: impact on procedural planning and team performance. Eur J Vasc Endovasc Surg. 53(3):354-361

39. Desender LM, Van Herzeele I, Lachat ML et al (2016) Patientspecific rehearsal before EVAR: influence on technical and nontechnical operative performance. A randomized controlled trial. Ann Surg. 264(5):703-709

40. Martin JA, Regehr G, Reznick R et al (1997) Objective structured assessment of technical skill (OSATS) for surgical residents. Br J Surg. 84(2):273-278

41. Maertens H, Aggarwal R, Moreels N, Vermassen F, Van Herzeele I (2017) A proficiency based stepwise endovascular curricular training (PROSPECT) program enhances operative performance in real life: a randomised controlled trial. Eur J Vasc Endovasc Surg. 54(3): 387-396

42. Grover SC, Garg A, Scaffidi MA et al (2015) Impact of a simulation training curriculum on technical and nontechnical skills in colonoscopy: a randomized trial. Gastrointest Endosc. 82(6):1072-1079

43. Cumpston M, Li T, Page MJ et al (2019) Updated guidance for trusted systematic reviews: a new edition of the Cochrane Handbook for Systematic Reviews of Interventions. Cochrane Database Syst Rev. 10:ED000142

44. Wolfram Alpha LLC (2009) Wolfram Alpha. https://www. wolframalpha.com/. Accessed Feb 1, 2019

45. The Cochrane Collaboration (2014) Review Manager (RevMan). https://community.cochrane.org/help/tools-and-software/revman-5. Accessed Feb 1, 2019

46. Waterman BR, Martin KD, Cameron KL, Owens BD, Belmont PJ (2016) Simulation training improves surgical proficiency and safety during diagnostic shoulder arthroscopy performed by residents. Orthopedics. 39(3):e479-e485

47. Dunn JC, Belmont PJ, Lanzi J, Martin K, Bader J, Owens B et al (2015) Arthroscopic shoulder surgical simulation training curriculum: transfer reliability and maintenance of skill over time. J Surg Educ. 72(6):1118-1123
48. Carlsen CG, Lindorff-Larsen K, Funch-Jensen P, Lund L, Konge L, Charles P (2015) Module based training improves and sustains surgical skills: a randomised controlled trial. Hernia. 19(5):755-763

49. Koch AD, Ekkelenkamp VE, Haringsma J, Schoon EJ, de Man RA, Kuipers EJ (2015) Simulated colonoscopy training leads to improved performance during patient-based assessment. Gastrointest Endosc. 81(3):630-636

50. Haycock A, Koch AD, Familiari P, van Delft F, Dekker E, Petruzziello L et al (2010) Training and transfer of colonoscopy skills: a multinational, randomized, blinded, controlled trial of simulator versus bedside training. Gastrointest Endosc. 71(2):298-307

51. Cohen J, Cohen SA, Vora KC, Xue X, Burdick JS, Bank S et al (2006) Multicenter, randomized, controlled trial of virtual-reality simulator training in acquisition of competency in colonoscopy. Gastrointest Endosc. 64(3):361-368

52. Zevin B, Dedy NJ, Bonrath EM, Grantcharov TP (2017) Comprehensive simulation-enhanced training curriculum for an advanced minimally invasive procedure: a randomized controlled trial. Surg Obes Relat Dis. 13(5):815-824

53. Satava RM (2010) Emerging trends that herald the future of surgical simulation. Surg Clin North Am. 90(3):623-633

54. Moiraghi A, Perin A, Sicky N et al (2020) EANS Basic Brain Course (ABC): combining simulation to cadaver lab for a new concept of neurosurgical training. Acta Neurochir (Wien).

55. Khan R, Plahouras J, Johnston BC, Scaffidi MA, Grover SC, Walsh CM (2019) Virtual reality simulation training in endoscopy: a Cochrane review and meta-analysis. Endoscopy. 51(7):653-664

56. Zendejas B, Brydges R, Wang AT, Cook DA (2013) Patient outcomes in simulation-based medical education: a systematic review. J Gen Intern Med. 28(8):1078-1089

57. Larsen CR, Oestergaard J, Ottesen BS, Soerensen JL (2012) The efficacy of virtual reality simulation training in laparoscopy: a systematic review of randomized trials. Acta Obstet Gynecol Scand. 91(9):1015-1028

58. Barber MD, Brubaker L, Nygaard I et al (2009) Defining success after surgery for pelvic organ prolapse. Obstet Gynecol. 114(3): 600-609

59. Cox T, Seymour N, Stefanidis D (2015) Moving the needle: simulation's impact on patient outcomes. Surg Clin North Am. 95(4): 827-838

60. Hopmans CJ, den Hoed PT, van der Laan L et al (2014) Assessment of surgery residents' operative skills in the operating theater using a modified Objective Structured Assessment of Technical Skills (OSATS): a prospective multicenter study. Surgery. 156(5):10781088

61. Siam B, Al-Kurd A, Simanovsky N et al (2017) Comparison of appendectomy outcomes between senior general surgeons and general surgery residents. JAMA Surg. 152(7):679-685

62. Reames BN, Bacal D, Krell RW, Birkmeyer JD, Birkmeyer NJ, Finks JF (2015) Influence of median surgeon operative duration on adverse outcomes in bariatric surgery. Surg Obes Relat Dis. 11(1):207-213

The corresponding author attests that all listed authors meet authorship criteria and that no others meeting the criteria have been omitted.

Publisher's note Springer Nature remains neutral with regard to jurisdictional claims in published maps and institutional affiliations. 